\title{
Assessment of $A L K$ gene fusions in lung cancer using the differential expression and exon integrity methods
}

\author{
QING HUANG $^{1}$, QIUHUA DENG ${ }^{2}$, LEI JIANG ${ }^{1}$, RONG FANG $^{1}$, YINGHUA QIU ${ }^{3}$, PING WANG $^{1}$, \\ JEFF X. ZHOU ${ }^{1}$ and HAIHONG YANG ${ }^{2}$ \\ ${ }^{1}$ Department of Pathology, Ningbo University School of Medicine, Ningbo, Zhejiang 315211; \\ ${ }^{2}$ Department of Thoracic Surgery, The First Affiliated Hospital, Guangzhou Medical University, Guangzhou, \\ Guangdong 510120; ${ }^{3}$ Unigene Bioscience Co., Ltd., Ningbo, Zhejiang 315211, P.R. China
}

Received November 25, 2014; Accepted November 11, 2015

DOI: $10.3892 / 01.2016 .4157$

\begin{abstract}
Anaplastic lymphoma kinase $(A L K)$ gene fusion is a driving mutation underlying the development of non-small cell lung cancer (NSCLC). Accurate detection of $A L K$ fusion is critical for the use of ALK inhibitors in the treatment of NSCLC. Commonly utilized methods for ALK detection include fluorescence in situ hybridization (FISH) and immunohistochemistry (IHC). However, these methods are time-consuming and costly. In the present study, a method for assessing $A L K$ gene fusion based on the differential expression levels of the $A L K$ kinase and non-kinase domains was developed and evaluated, with the aim of providing a convenient and reliable method for the detection of $A L K$ fusion. In addition, another method was established to determine the integrity of exons 19-20 and 20-21 of $A L K$, two genomic loci that are typically broken in $A L K$ fusions. These novel methods were applied to detect $A L K$ fusion in 100 NSCLC patients, and were compared with IHC and FISH methods. The novel methods developed in the present study successfully detected $A L K$ fusions in 10 samples. The concordances between the novel methods and IHC and FISH were $100 \%$. Furthermore, the differential expression method was able to detect $A L K$ fusions in cell-free urine samples, which was advantageous over FISH and IHC. The novel methods developed in the present study are cost-effective and easy to perform, and may provide simple and convenient techniques for the clinical assessment of $A L K$ fusions, facilitating the use of targeted therapy for NSCLC.
\end{abstract}

Correspondence to: Dr Jeff X. Zhou, Department of Pathology, Ningbo University School of Medicine, 818 Fenghua Road, Ningbo, Zhejiang 315211, P.R. China

E-mail: zhouxiwu@nbu.edu.cn

Dr Haihong Yang, Department of Thoracic Surgery, The First Affiliated Hospital, Guangzhou Medical University, 151 Yanjiang Road, Guangzhou, Guangdong 510120, P.R. China

E-mail: bjrf2009@yahoo.com

Key words: anaplastic lymphoma kinase, lung cancer, targeted therapy, crizotinib

\section{Introduction}

Anaplastic lymphoma kinase $(A L K)$ gene rearrangement is a driving mutation underlying the development of non-small cell lung cancer (NSCLC) $(1,2)$. The most commonly observed type of $A L K$ rearrangement is a fusion with echinoderm microtubule associated protein like $4(E M L 4)$ as a result of the inversion of chromosome $2(1,2)$. A total of $5-7 \%$ of NSCLC tumors harbor EML4-ALK fusion (3). In addition to $E M L 4, A L K$ has been identified to fuse with other partner genes, including nucleophosmin (NPMI), tropomyosin 3 and vinculin (4). Targeted therapeutic agents, including crizotinib, have shown clinical efficacy in treating NSCLC patients harboring EML4-ALK gene fusion (5). Furthermore, a previous study demonstrated that crizotinib is additionally effective at treating tumors harboring $A L K$ fused with other partner genes, including NPMI (6).

A prerequisite for the effective use of targeted therapy is the accurate detection of molecular targets in tumors. For $A L K$ rearrangement detection, the U.S. Food and Drug Administration (FDA)-approved method for companion diagnostics is fluorescence in situ hybridization (FISH), which measures the physical integrity of the $A L K$ gene in chromosome 2 (7). However, previous studies have identified that FISH is prone to technical difficulties, which may lead to non-interpretable results $(8,9)$. In addition, FISH is unable to detect genomic gain or overexpression of the $A L K$ gene (10). FISH is also an expensive and time-consuming method, and requires a high degree of technological expertise for its operation (11). Immunohistochemistry (IHC) is another method commonly used clinically for ALK detection in tumor tissues (8-10); it detects the levels of ALK protein, rather than gene rearrangement, in tumor cells. Studies have revealed that results obtained using IHC are highly concordant with those obtained using FISH $(8,9)$, and IHC is able to capture ALK-positive tumors that are not detected using FISH $(9,10)$. However, IHC is a time-consuming method, its success is subject to antibody quality and the experience of technologists, and the interpretation of IHC results is subjective (12). Reverse transcription polymerase chain reaction (RT-PCR) has been used for the detection of $A L K$ fusion (13-15). The shortcoming of RT-PCR is that multiple reactions are typically required to cover 
various forms of $A L K$ fusions, thus requiring a relatively large quantity of clinical samples (13). In order to maximize the number of NSCLC patients able to benefit from ALK-targeted therapy, there is a requirement for the development of a simple yet comprehensive method for the detection of $A L K$ rearrangements.

In its rearranged forms, $A L K$ typically breaks between exons 19 and 20 or 20 and 21, leaving its kinase domain intact, which is then able to fuse with a partner gene (4). Taking advantage of this feature, the present study developed a simple technique, named the differential expression method, to assess $A L K$ fusion via measurement of the relative expression levels of the kinase and non-kinase domains. In addition, the present study developed a complementary method, named the exon integrity method, for detection of the integrity of exons $19-20$ and 20-21 as an indicator of $A L K$ breaks at these loci.

\section{Materials and methods}

NSCLC cells and clinical samples. The NCI-H3122 human NSCLC cell line ( $A L K$ fusion-positive) was provided by AstraZeneca Innovation Center (Shanghai, China). The NCI-H2228 human NSCLC cell line ( $A L K$ fusion-positive) and A549 cells ( $A L K$ fusion-negative) were purchased from the American Type Culture Collection (Manassas, VA, USA). The cells were cultured in Dulbecco's modified Eagle's medium (Hyclone; GE Healthcare Life Sciences, Logan, UT, USA) supplemented with $10 \%$ fetal bovine serum(Ausgenex Pty Ltd., Molindar, Australia), $100 \mathrm{U} / \mathrm{ml}$ penicillin and $100 \mathrm{U} / \mathrm{ml}$ streptomycin (GE Healthcare Life Sciences) at $37^{\circ} \mathrm{C}$ in an atmosphere of $5 \% \mathrm{CO}_{2}$.

The use of clinical samples for the present study was approved by the Ethics Committees of the First Affiliated Hospital of Guangzhou Medical University (Guangzhou, China) and Ningbo University School of Medicine (Ningbo, China) and informed consent was received from all patients. Formalin-fixed, paraffin-embedded (FFPE) tissues from 100 NSCLC patients were originally used for screening of ALK expression using an anti-ALK (D5F3) IHC assay (Ventana Medical Systems, Inc., Tucson, AZ, USA) based on the manufacturer's protocols. Sections of the IHC-positive samples were additionally analyzed using a Vysis LSI ALK Break Apart Rearrangement FISH Probes system based on the manufacturer's protocols (Abbott Molecular, Des Plaines, IL, USA). In addition, two urine samples from NSCLC patients with $A L K$ fusion positivity detected using FISH were obtained and used for testing the detection methods developed in the present study.

Differential expression method design. The pathological consequence of $A L K$ fusion in tumor cells is the overexpression of the $A L K$ kinase domain compared with the non-kinase domain. Based on this fact, a differential expression method was designed by measuring the expression levels of the $A L K$ kinase and non-kinase domains simultaneously, and using the difference in expression levels as an indicator of $A L K$ gene fusion. The $A L K$ gene has 29 exons, with the kinase domain spanning from exons 20-29 and the non-kinase domain spanning from exons 1-19 (1). Among a series of candidate sequences, a sequence located between exons 24-26 was selected for the kinase domain, and a sequence between exons 12-13 was selected for the non-kinase domain. For the measurement of the two domains, the forward and reverse primers were located in different exons, and the probe was located between the primers (Fig. 1). The sequences of primers and probes used are listed in Table I. The transcript levels of the $A L K$ kinase and non-kinase domains were measured using TaqMan probe-based quantitative (q)PCR. The quantification cycle $(\mathrm{Cq})$ values of the non-kinase domain $(\mathrm{NK})$ and the kinase domain $(\mathrm{K})$ were used for calculating the differential expression levels of these two domains as $\mathrm{D}=2^{\Delta \mathrm{Cq}}$, where $\Delta \mathrm{Cq}=\mathrm{Cq}(\mathrm{NK})-\mathrm{Cq}(\mathrm{K})$. When $\triangle \mathrm{Cq}$ was $\geq 1$, this indicated that the levels of $A L K$ kinase domain were twice (when $\Delta \mathrm{Cq}=1, \mathrm{D}=2$ ) or more than twice (when $\Delta \mathrm{Cq}>1, \mathrm{D}>2$ ) that of the non-kinase domain, and the sample was deemed to be $A L K$ fusion-positive.

Exon integrity method design. The exon integrity method is based on the fact that $A L K$ fusion results from the break of the gene, thus destroying the integrity of the $A L K$ locus. $A L K$ breakpoints are typically located at exons $19-20$ or 20-21 (1,2). By measuring the amplificability of exons 19-20 and 20-21 using qPCR, the integrity of the $A L K$ gene may be assessed and used as an indicator of $A L K$ fusion. An identical strategy is employed by FISH technology for assessing $A L K$ fusion (5). The sequences of primers utilized are summarized in Table I.

$q P C R$. Total RNA was isolated from cultured cells, FFPE tissues or urine using UniGene total RNA isolation kits (UniGene Bioscience Co., Ltd, Ningbo, China). For urine RNA isolation, $15 \mathrm{ml}$ urine was centrifuged for $15 \mathrm{~min}$ at $400 \mathrm{x} \mathrm{g}$ at $4^{\circ} \mathrm{C}$ to remove cells, and subsequently mixed with an equal volume of $8 \mathrm{M}$ guanidine thiocyanate (Sigma-Aldrich, St. Louis, MO, USA) and loaded onto a silica-based spin column (UniGene Bioscience Co., Ltd). Total RNA was transcribed into complementary (c)DNA using a reverse-transcription kit (UniGene Bioscience Co., Ltd). The levels of complementary (c)DNA at exons 24-26 and 12-13 of ALK were measured using qPCR systems (Roche Diagnostics, Shanghai, China) with a Roche 480 II RT-PCR instrument (Roche Diagnostics). The levels of cDNA at exons 19-20 and 20-21 of $A L K$ were measured using SYBR Green Master Mix (Roche Diagnostics). The qPCR reactions were conducted as follows: $95^{\circ} \mathrm{C}$ for $10 \mathrm{~min}$, amplification for 40 cycles of $95^{\circ} \mathrm{C}$ for $15 \mathrm{sec}$ (denaturation) and $61^{\circ} \mathrm{C}$ for $1 \mathrm{~min}$ (annealing and extension). For each reaction, the levels of glyceraldehyde-3-phosphate dehydrogenase transcripts were measured as a control for the loading amount of cDNA.

Statistical analysis. Data were analyzed for statistical significance using Student's t-test or Fisher's exact test as appropriate. $\mathrm{P}<0.05$ was considered to indicate a statistically significant difference. All statistical analyses were performed using SPSS software, version 18.0 (SPSS, Inc., Chicago, IL, USA).

\section{Results}

Differential expression method demonstrates the ability to detect ALK fusion. Based on the pathological consequences of $A L K$ fusion, including aberrantly high expression levels, and the activities of the ALK kinase domain driven by the high transcription activity of the partner gene, a strategy for 
Table I. Sequences of primers and probes used in the differential expression and exon integrity method experiments.

\begin{tabular}{ll}
\hline Method & Sequence $\left(5^{\prime}-3^{\prime}\right)$
\end{tabular}

\section{Differential expression}

Kinase domain

Non-kinase domain

Exon integrity

$A L K$ exons 19-20

ALK exons 20-21
F: GAAAACCACTTCATCCACCG

R: TGGCACAGCCTCCCTTTCTAT

Probe: FAM-CGTGCCAGAAACTGCCTCTTGAC-BHQ1

F: TGCCAGCCACCGACACCTA

R: TTGAAGATGCCCAGCACAGA

Probe: HEX-ATGGTGTTCTTCCCGCCTTTCCCG-BHQ1

F: ACTCTCGCTGATCCTCTCTG

R: TTGCTCAGCTTGTACTCAGG

F: CCGACTACAACCCCAACTAC

R: CCTTCATACACCTCCCCAAAG

$\mathrm{F}$, forward primer; $\mathrm{R}$, reverse primer; $A L K$, anaplastic lymphoma kinase.

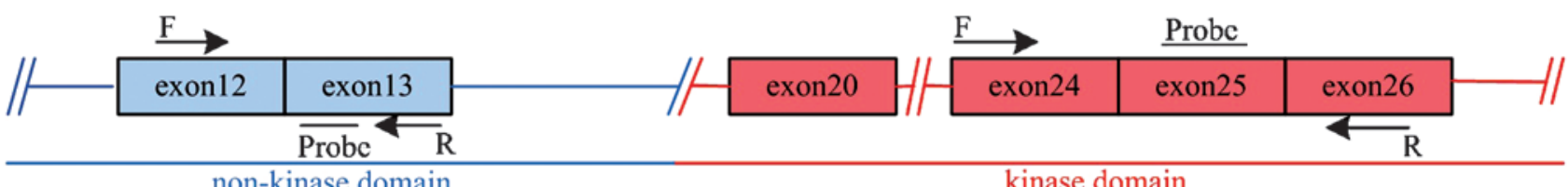

Figure 1. Schematic demonstration of the design of the differential expression method. The locations of primers and probes for the kinase domain (red) and non-kinase domain (blue) of anaplastic lymphoma kinase are shown. F, forward primer; R, reverse primer.

A

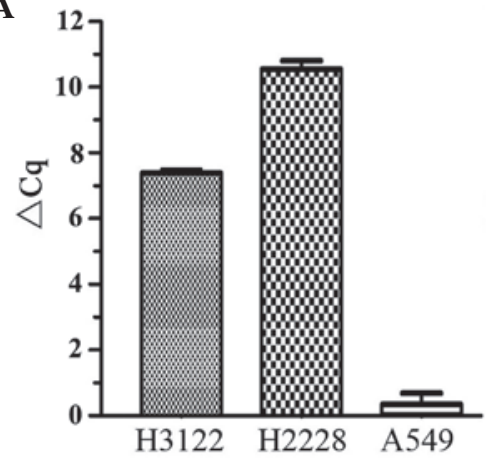

B

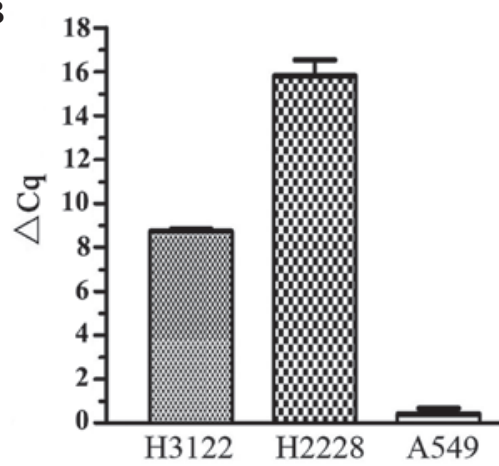

Figure 2. Performance of the differential expression and exon integrity methods. ALK fusion-positive H3122 and H2228 cells, as well as $A L K$ fusion-negative A549 cells, were used for testing the two methods. (A) For the differential expression method, the differences in Cq values of the $A L K$ kinase domain and non-kinase domain $(\triangle \mathrm{Cq})$ in the H3122, H2228 and A549 cells are shown. Cells with $\triangle \mathrm{Cq}$ values $\geq 1$ were deemed to be $A L K$ fusion-positive. (B) For the exon integrity method, the differences in the Ct values of exons 19-20 and 20-21 amplification ( $\Delta \mathrm{Cq})$ in the H3122, H2228 and A549 cells are shown. H3122 and $\mathrm{H} 2228$ cells had increased amplification values for exons 20-21 compared with exons 19-20. A549 cells had low levels of ALK expression. ALK, anaplastic lymphoma kinase; $\mathrm{Cq}$, quantification cycle.

assessing $A L K$ fusion by measuring the differential expression levels of the $A L K$ kinase and non-kinase domains was designed. To test this design, $A L K$ fusion-positive $\mathrm{H} 3122$ and $\mathrm{H} 2228$ cells, and $A L K$ fusion-negative A549 cells were initially used to measure the differential expression levels of the $A L K$ kinase and non-kinase domains. $A L K$ gene break-apart occurs at exons 19-20 in H3122 and H2228 cells (12). The results of the present study demonstrated that the average $\Delta \mathrm{Cq}$ for the $\mathrm{H} 3122, \mathrm{H} 2228$ and A549 cells was 7.3, 10.3 and 0.5, respectively (Fig. 2A). Therefore, in the H3122 and H2228 cells, the levels of kinase domain transcripts were 158 times $\left(2^{7.3}\right)$ and 1,261 times $\left(2^{10.3}\right)$ greater compared with that of the non-kinase domain transcripts, respectively. In A549 cells, there was no differential expression observed between the kinase domain and domains of $A L K$, as $\triangle \mathrm{Cq}<1$. The effect of the input amount of cDNA was also investigated, and it was observed that the $\triangle \mathrm{Cq}$ values were constant and independent of input cDNA quantities (data not shown). The results of the present study clearly demonstrated the ability of the differential expression method to detect $A L K$ fusion. 
Table II. Performance of the differential expression and exon integrity methods compared with IHC.

\begin{tabular}{lrr}
\hline & \multicolumn{2}{c}{ IHC } \\
\cline { 2 - 3 } Method & + & \\
\hline Differential expression & & \\
+ & 10 & 0 \\
- & 0 & 90 \\
Exon integrity & & 0 \\
+ & 8 & 90 \\
- & 2 & \\
\hline
\end{tabular}

IHC, immunohistochemistry.

Table III. Detection of anaplastic lymphoma kinase fusion in urine from non-small cell lung cancer patients using the differential expression method.

\begin{tabular}{lcc}
\hline & \multicolumn{2}{c}{ Differential expression method } \\
\cline { 2 - 3 } Sample & Kinase domain & Non-kinase domain \\
\hline FISH $^{+}$sample 1 & 33.35 & - \\
FISH $^{+}$sample 2 & 30.13 & - \\
Healthy control 1 & - & - \\
Healthy control 2 & - & - \\
NCI-H3122 & 24.53 & 31.52 \\
$\mathrm{H}_{2} \mathrm{O}$ & - & -
\end{tabular}

'-' denotes that the Ct value was below the cut-off value of 36 . FISH, fluorescence in situ hybridization.

Exon integrity method reveals amplification at exons 19-20 and 20-21. In addition to the differential expression method, another method was developed to assess the integrity of exons 19-20 and 20-21, two loci that are frequently broken in $A L K$ fusions, via amplification of cDNA across these exons. The results showed that for H3122 and H2228 cells, cDNA across exons 19-20 and 20-21 was amplified. However, the levels of cDNA across exons 19-20 were 375 times $\left(2^{8.55}\right)$ and 15,936 times $\left(2^{13.96}\right)$ less than that across exons 20-21 in the H3122 cells and H2228 cells, respectively (Fig. 2B). For the A549 cells, transcripts across exons 19-20 and 20-21 were expressed at low levels, and there were no differences between them, indicating that there were no breakpoints at these two loci.

Differential expression and exon integrity methods validated using clinical samples. Following the establishment of the methods using $\mathrm{H} 3122$ and $\mathrm{H} 2228$ cells, the performance of these methods was tested using 100 NSCLC tumor FFPE samples. Of these NSCLC samples, 10 (10\%) were observed to be ALK-positive using the VENTANA ALK IHC method (Fig. 3A). Of these 10 ALK IHC-positive samples, 3 were
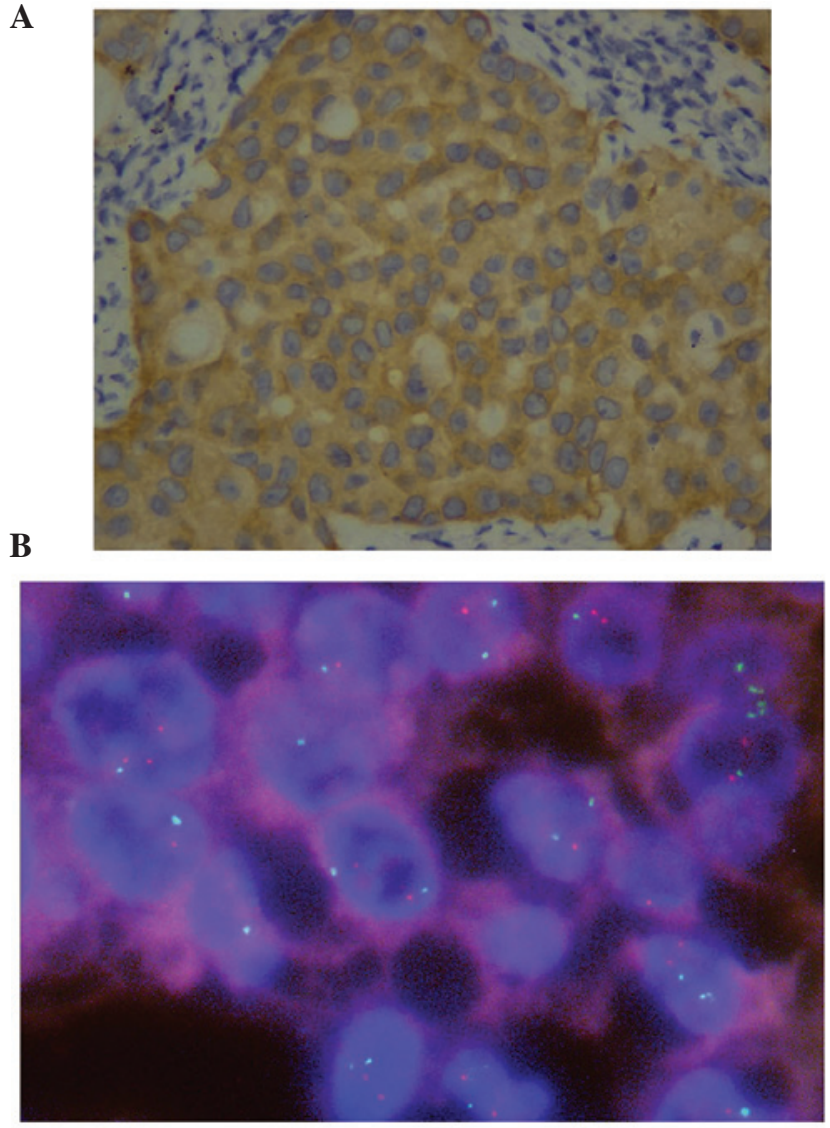

Figure 3. Representative results of (A) IHC (x400 magnification) and (B) FISH (x1,000 magnification) detection in non-small cell lung cancer tissues. For FISH, the separation of red and green signals indicated the break apart of chromosome 2 at the anaplastic lymphoma kinase locus. IHC, immunohistochemistry; FISH, fluorescence in situ hybridization.

further analyzed using FISH, and all were identified to be FISH-positive (Fig. 3B).

The differential expression method was initially used to detect $A L K$ fusions in these NSCLC samples in a double-blind manner. It was identified that the kinase domain was successfully amplified in 10 samples (10\%), while the non-kinase domain was amplified in only 1 of these 10 samples. For the sample with non-kinase domain amplification, the expression levels of kinase domain were 9.19 times $\left(2^{3.2}\right)$ greater compared with that of the non-kinase domain. The results therefore indicated that these 10 samples were $A L K$-fusion-positive. By checking the identities of these samples, it was identified that the results of the differential expression method were in $100 \%$ concordance with the IHC results (Table II). Subsequently, the exon integrity method was used to test the 10 positive samples, and it was identified that exon 20-21 sequences were amplified in 8/10 samples; however, the exon 19-20 sequences were not amplified (Table II).

The applicability of the methods for detection of $A L K$ fusion was additionally investigated in liquid samples. Using cell-free urine samples collected from two NSCLC patients whose tumors were $A L K$ fusion-positive as detected by FISH, the differential expression method successfully detected the amplification of the kinase domain, but not the non-kinase domain of ALK (Table III). The cDNA from H3122 cells served as a positive control, and cDNA from cell-free urine 
collected from two healthy women served as a negative control.

\section{Discussion}

Accurate and convenient methods for detecting drug targets in tumor cells are critical for the implementation of targeted therapies for the treatment of cancer. ALK fusion with EML4 or alternative partner genes has been recognized as an effective target for ALK inhibitors, including crizotinib, for the treatment of NSCLC (16). As a companion diagnostics approach approved by the FDA, FISH-based methods detect $A L K$ fusion in tumor cells by determining the physical integrity of $5^{\prime}$ and $3^{\prime}$ portions of the $A L K$ gene. FISH-based methods have an advantage in that the general morphology of tumor cells and the physical integrity of chromosome 2 may be observed simultaneously. However, FISH methods are expensive, require a high degree of technological expertise and frequently produce non-interpretable results $(7,8)$. By contrast, IHC is able to detect the levels of ALK protein, and several commercial systems with specific monoclonal antibodies against ALK protein are available $(7,8)$. However, the protocol for IHC is complex and time-consuming, and final results of IHC are subject to antibody quality and pathologist experience (12).

Considering the limitations of FISH and IHC, two transcript-based methods were developed for assessment of $A L K$ fusion in the present study. The differential expression method was based on the pathological consequences of $A L K$ gene fusion, which are aberrantly high levels of the ALK kinase domain. The exon integrity method was based on the break of the gene locus when $A L K$ fusion occurs, a strategy similar to the FISH method. The results of the present study clearly demonstrated the applicability of these two methods for the assessment of $A L K$ fusion. Compared with FISH and IHC, the methods used in the present study were easier to perform and cheaper in cost. Furthermore, the differential expression method directly measured the levels of the $A L K$ kinase domain in comparison with its non-kinase domain, which gave it an advantage over FISH, which only detects the physical integrity of chromosome 2 . Similar to the differential expression method, IHC detects the total levels of ALK protein in tumor tissues, rather than the fusion of ALK (17). Factors leading to increases in the protein levels of ALK include: Gene fusion, gene amplification, genomic gain or regulations at transcriptional or post-transcriptional levels (18). Theoretically, ALK inhibitors would be effective in treating tumors exhibiting high levels of ALK regardless of the causes leading to the overexpression of this kinase. However, there is little information regarding the comparison of performances between IHC and FISH in terms of their power for predicting patient responsiveness to ALK inhibitors.

Although tumor tissues are the optimum sample for gene mutation detection, it is frequently difficult to collect a sufficient amount of tissue samples. In certain cases, it may be impossible to obtain tumor tissue samples. Therefore, liquid biopsy represents a positive source for the assessment of tumor-associated gene mutations. Liquid samples, including plasma, have been used for the detection of mutations in epidermal growth factor receptor, $B R A F$ and Kirsten rat sarcoma viral oncogene homolog in NSCLC patients (19). In the present study, using the differential expression method, $A L K$ fusion was successfully detected in cell-free urine samples. To the best of our knowledge, this is the first report indicating that urine can be used for the assessment of $A L K$ fusion in NSCLC patients. Therefore, the method devised in the present study would provide a novel non-invasive approach for the assessment of driving mutations, including $A L K$ fusion, and for the monitoring of disease progression in NSCLC patients.

It should be noted that although the methods utilized in the present study were validated using 100 NSCLC tumor samples, these NSCLC patients did not receive ALK inhibitor in their treatment regimens. To confirm the usefulness of the methods developed in the present study for the prediction of patient responsiveness to ALK inhibitors, validation of these methods is required using samples from NSCLC patients receiving crizotinib treatment.

In conclusion, the present study developed two methods for the assessment of $A L K$ fusion in NSCLC tumor and urine samples. These methods would provide simple yet comprehensive approaches to clinical practice for the selection of patients that may benefit from treatment with ALK inhibitors, and the monitoring of treatment efficacy and disease progression.

\section{Acknowledgements}

The present study was supported by the Science and Technology Plan of Zhejiang Province of China (grant no. 2013C33165) and the National Natural Science Fund for Distinguished Young Scholars (grant no. 81302000).

\section{References}

1. Soda M, Choi YL, Enomoto M, Takada S, Yamashita Y, Ishikawa S, Fujiwara S, Watanabe H, Kurashina K, Hatanaka H, et al: Identification of the transforming EML4-ALK fusion gene in non-small-cell lung cancer. Nature 448: 561-566, 2007.

2. Takeuchi K, Choi YL, Soda M, Inamura K, Togashi Y, Hatano S, Enomoto M, Takada S, Yamashita Y, Satoh Y, et al: Multiplex reverse transcription-PCR screening for EML4-ALK fusion transcripts. Clin Cancer Res 14: 6618-6624, 2008.

3. Zhou JX, Yang H, Deng Q, Gu X, He P, Lin Y, Zhao M, Jiang J, Chen H, Lin Y, et al: Oncogenic driver mutations in patients with non-small-cell lung cancer at various clinical stages. Ann Oncol 24: 1319-1325, 2013.

4. Mano H: ALKoma: A cancer subtype with a shared target. Cancer Discov 2: 495-502, 2012

5. Kwak EL, Bang YJ, Camidge DR, Shaw AT, Solomon B, Maki RG, Ou SH, Dezube BJ, Jänne PA, Costa DB, et al: Anaplastic lymphoma kinase inhibition in non-small-cell lung cancer. N Engl J Med 363: 1693-1703, 2010.

6. Mossé YP, Lim MS, Voss SD, Wilner K, Ruffner K, Laliberte J, Rolland D, Balis FM, Maris JM, Weigel BJ, et al: Safety and activity of crizotinib for paediatric patients with refractory solid tumours or anaplastic large-cell lymphoma: A Children's Oncology Group phase 1 consortium study. Lancet Oncol 14: 472-480, 2013.

7. Di Maio M, De Marinis F, Hirsch FR and Gridelli C: Diagnostic and therapeutic issues for patients with advanced non-small cell lung cancer harboring anaplastic lymphoma kinase rearrangement: European vs. US perspective (Review). Int J Oncol 45: 509-515, 2014.

8. von Laffert M, Warth A, Penzel R, Schirmacher P, Kerr KM, Elmberger G, Schildhaus HU, Büttner R, Lopez-Rios F, Reu S, et al: Multicenter immunohistochemical ALK-testing of non-small-cell lung cancer shows high concordance after harmonization of techniques and interpretation criteria. J Thorac Oncol 9: 1685-1692, 2014.

9. McLeer-Florin A, Moro-Sibilot D, Melis A, Salameire D, Lefebvre C, Ceccaldi F, de Fraipont F, Brambilla E and Lantuejoul S: Dual IHC and FISH testing for ALK gene rearrangement in lung adenocarcinomas in a routine practice: A French study. J Thorac Oncol 7: 348-354, 2012. 
10. Ilie MI, Bence C, Hofman V, Long-Mira E, Butori C, Bouhlel L, Lalvée S, Mouroux J, Poudenx M, Otto J, et al: Discrepancies between FISH and immunohistochemistry for assessment of the ALK status are associated with ALK 'borderline'-positive rearrangements or a high copy number: A potential major issue for anti-ALK therapeutic strategies. Ann Oncol 26: 238-244, 2015.

11. Ali G, Proietti A, Pelliccioni S, Niccoli C, Lupi C, Sensi E, Giannini R, Borrelli N, Menghi M, Chella A, et al: ALK rearrangement in a large series of consecutive non-small cell lung cancers: Comparison between a new immunohistochemical approach and fluorescence in situ hybridization for the screening of patients eligible for crizotinib treatment. Arch Pathol Lab Med 138: 1449-1458, 2014

12. Wong DW, Leung EL, So KK, Tam IY, Sihoe AD, Cheng LC, Ho KK, Au JS, Chung LP and Pik WM: The EML4-ALK fusion gene is involved in various histologic types of lung cancers from nonsmokerswith wild-type EGFR and KRAS. Cancer 115: 1723-1733, 2009.

13. Soda M, Isobe K, Inoue A, Maemondo M, Oizumi S, Fujita Y, Gemma A, Yamashita Y, Ueno T, Takeuchi K, et al; North-East Japan Study Group; ALK Lung Cancer Study Group: A prospective PCR-based screening for the EML4-ALK oncogene in non-small cell lung cancer. Clin Cancer Res 18: 5682-5689, 2012.

14. Pan Y, Zhang Y, Li Y, Hu H, Wang L, Li H, Wang R, Ye T, Luo X, Zhang Y, et al: ALK, ROS1 and RET fusions in 1139 lung adenocarcinomas: A comprehensive study of common and fusion pattern-specific clinicopathologic, histologic and cytologic features. Lung Cancer 84: 121-126, 2014.
15. Koivunen JP, Mermel C, Zejnullahu K, Murphy C, Lifshits E, Holmes AJ, Choi HG, Kim J, Chiang D, Thomas R, et al: EML4-ALK fusion gene and efficacy of an ALK kinase inhibitor in lung cancer. Clin Cancer Res 14: 4275-4283, 2008.

16. Rolfo C, Passiglia F, Castiglia M, Raez LE, Germonpre P, Gil-Bazo I, Zwaenepoel K, De Wilde A, Bronte G, Russo A, et al: ALK and crizotinib: After the honeymoon... what else? Resistance mechanisms and new therapies to overcome it. Transl Lung Cancer Res 3: 250-261, 2014.

17. Teixidó C, Karachaliou N, Peg V, Gimenez-Capitan A and Rosell R: Concordance of IHC, FISH and RT-PCR for EML4-ALK rearrangements. Transl Lung Cancer Res 3: 70-74, 2014.

18. Weickhardt AJ, Aisner DL, Franklin WA, Varella-Garcia M, Doebele RC and Camidge DR: Diagnostic assays for identification of anaplastic lymphoma kinase-positive non-small cell lung cancer. Cancer 119: 1467-1477, 2013.

19. Oxnard GR, Paweletz CP, Kuang Y, Mach SL, O'Connell A, Messineo MM, Luke JJ, Butaney M, Kirschmeier P, Jackman DM and Jänne PA: Noninvasive detection of response and resistance in EGFR-mutant lung cancer using quantitative next-generation genotyping of cell-free plasma DNA. Clin Cancer Res 20: $1698-1705,2014$ 